\title{
OPTIMIZATION OF WELDING PROCESS USING A GENETIC ALGORITHM
}

\author{
ÉLESZTŐS Pavel, JANČO Roland, VOŠTIAR Vladimír \\ Slovak University of Technology in Bratislava, Faculty of Mechanical Engineering, Institute of Applied \\ Mechanics and Mechatronics, Nam. slobody 17, 81231 Bratislava, Slovak Republic, email: \\ pavel.elesztos@stuba.sk
}

\begin{abstract}
Welding is a complex technological process in which local heating takes place up to the melting point of the connecting and the additional material. Phase and crystallization processes are a strong non-linear function of the cooling rate. This non-linear function multiplies the complexity of the numerical simulation and optimization of the welding process. Lately, optimization with genetic algorithm has become the trend to optimize systems that behave in a non-linear manner and contain a number of local extremes. Genetic algorithm is therefore a method by which we seek an absolute extreme. It is a method which seeks a solution to near absolute extreme. In this paper the use of the genetic algorithm for welding process optimization is described.
\end{abstract}

KEYWORDS: Optimization, welding, genetic algorithm, finite element method.

\section{Introduction}

Welding is a technological process that is most commonly used in manufacturing of industrial equipment for the creation of rigid joints as well as for the repair of various design defects found after manufacturing or in various defectoscopic service inspections. The disadvantage of this technology is that in the structure there may be permanent deformations and stresses, often of undesirable sizes. Therefore, there is a natural requirement to minimize the adverse effects of using the welding process. Unfortunately, it is not possible to carry out an experiment on a real construction when repairing components $[1,2,5]$. Therefore, a process with such technological parameters must be chosen so that the resulting deformation-voltage state is permissible, and the surrounding part of the structure is minimally affected. When choosing the welding technology parameters, the options of numerical solutions, where it is possible to simulate different welding designs to achieve the required minimization of negative welding effects, are numerous. Time and the financial advantage of "experimentation" with numerical simulation are also key factors.

To create a corresponding numerical model, it is necessary (at least in some cases) to carry out experimental measurements on a sample of the same material and with the same parameters of the technology that is to be used in the actual case of welding. After obtaining the parameters with which the numerical model is set, it is possible to simulate the welding of any structural part using the same parameters of the technology and using the same material as the one used in the experiment, or when setting up a numerical model. Having created the corresponding numerical model, the optimization tool can be applied, and in the case of welding processes it is a genetic algorithm that finds a solution with minimal negative impact on the welding environment $[6,7,8,9,10,11]$.

The detailed sequence of the problem of welding optimization using the genetic algorithm is shown in Fig. 1. 


\begin{tabular}{|c|c|}
\hline Stages of problem solving & $\begin{array}{c}\text { Outputs of the corresponding stage } \\
\text { solutions }\end{array}$ \\
\hline Experimental measurements & $\begin{array}{c}\text { Temperature diagram records by } \\
\text { thermocouples and the course of storage } \\
\text { responses }\end{array}$ \\
\hline $\begin{array}{c}\text { Setting the numeric simulation parameters } \\
\text { based on the experiment }\end{array}$ & $\begin{array}{c}\text { Correctly set numerical simulation parameters } \\
\text { corresponding to the experiment }\end{array}$ \\
\hline $\begin{array}{c}\text { Creating the FEM model for a specific } \\
\text { case of welding optimization }\end{array}$ & FEM model in program SYSWELD \\
\hline Optimization by genetic algorithm & Solution close to the optimal solution \\
\hline
\end{tabular}

Fig. 1 Stages of the solution

\section{Experimental measurements and numerical model setting}

Experimental measurements were performed on a sample of which geometric parameters and joining are shown in Fig. 2 and Fig. 3.

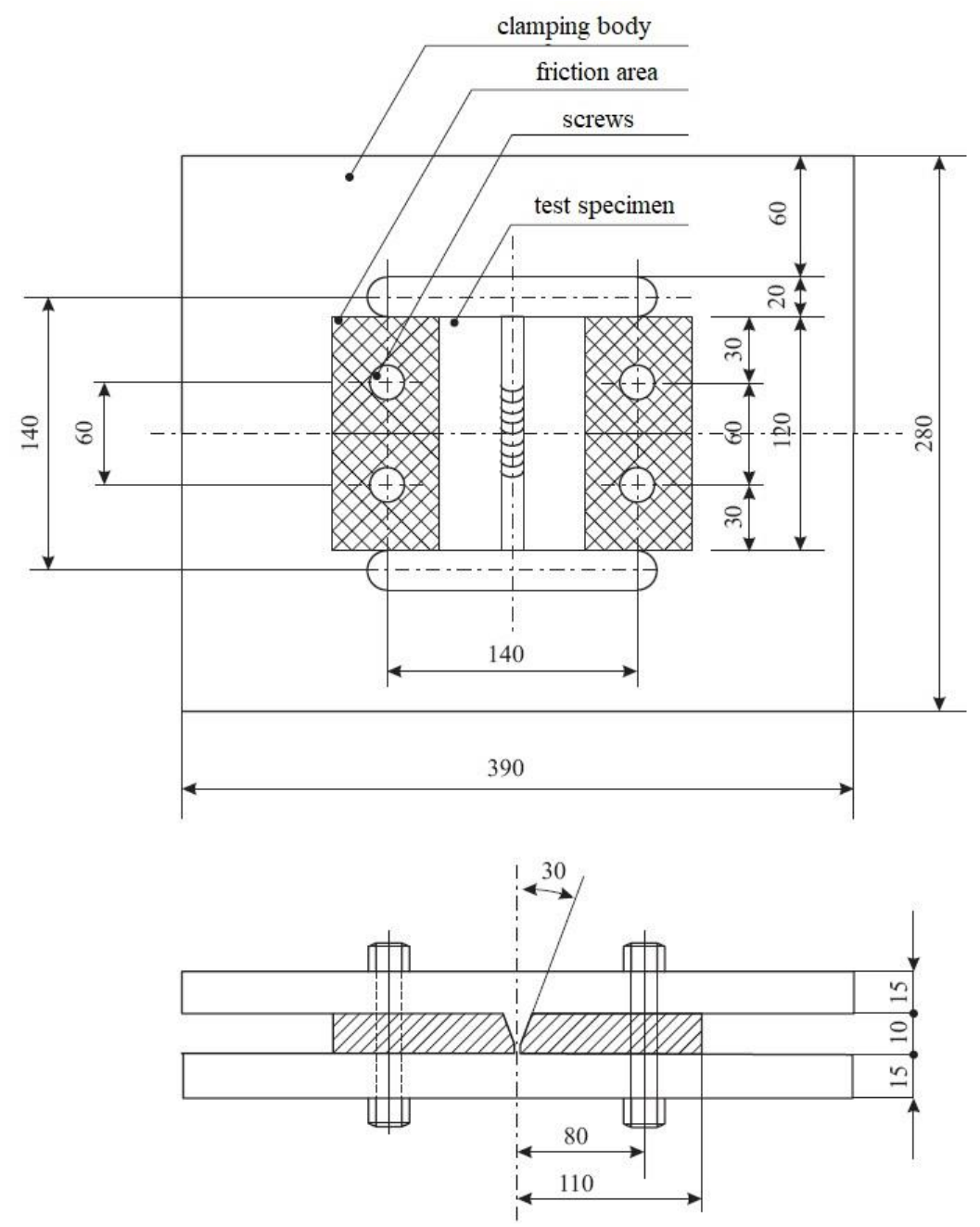

Fig. 2 Sample joining mechanism 


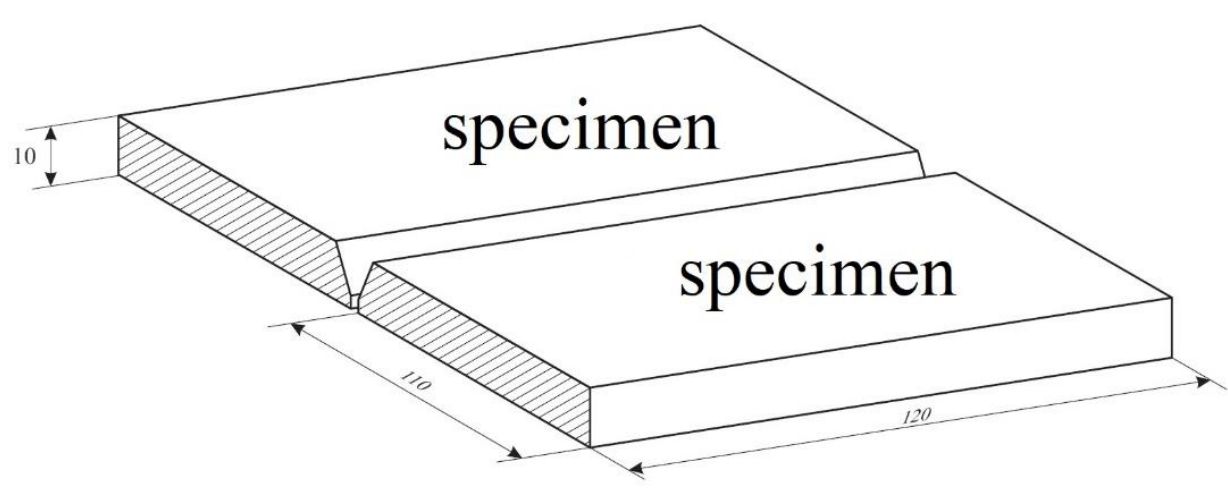

Fig. 3 Experimental sample

The prepared bevelled samples (two flat plates) were welded with a single-layer weld. During the welding process, welding temperatures were recorded, as well as the reactive forces in the support to capture the mechanical effects of the welding. Based on the data obtained from the experimental measurement, a numerical model of the heat source was created in SYSWELD [4]. Temperatures obtained by the experimental measurement and the process calculated numerically with the help of the already set numerical model of the heat source and using the identical material parameters can be observed in Fig 5. and Fig. 6. Compared temperature curves were measured, and numerically evaluated in areas indicated in Fig. 4.

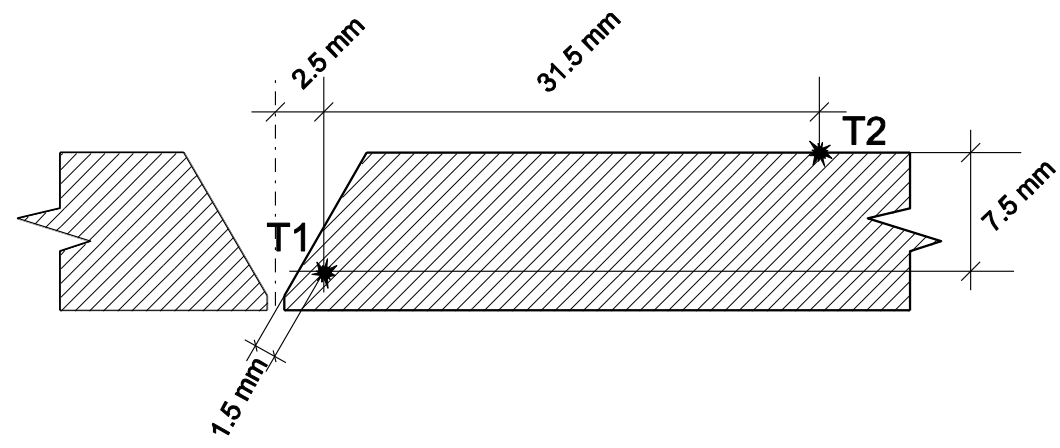

Fig. 4 Location of thermocouples

\section{Model of optimized sample}

The numerical model set up based on the experimental measurement can be used for the simulation of different structural parts using the same materials and parameters of the technology. For example, a welding optimization model using the genetic algorithm was chosen to model the welding layer of the additive material around the perimeter of the opening (Fig. 7). In this case, the welding layer can be welded in sections (5 sections) in different order and in different directions (clockwise and anti-clockwise). The aim of the optimization was to find a combination of the welding sequence and its welding directions to keep the resulting maximum deformation to minimum.

\section{Genetic algorithm for welding optimization}

The genetic algorithm works with the binary string (the string contains the digits " 0 " and "1"), or with the real number chain or the combined chain. Each string encodes one solution, and of course, one resulting state that is reassessed by the function so that the algorithm is able to evaluate the ability of the given chain (s) to participate in the generation of the next generation and thus be a potential solution to the optimization process. 
In our specific case, a string consisting of 10 values (10 bits) was created, the first 5 digits coding the sequence of the welding segments, and the other 5 digits coding the direction of welding in the given section. The first position in the chain (the first stretch of welding) was bound to the sixth position in the chain that prescribed the direction of welding [3]. Gradually, the second and seventh positions were bound together, etc. This way, we were able to encode one piece of additional material in the range of one revolution. Logically, each string represents one resulting voltage-strain state, based on what each string has been assigned a function of suitability. The fitness function was chosen with the intention of obtaining a solution with a minimal maximum residual strain by means of the genetic chain optimization process. Chains (solutions) that are assigned a unique feature of suitability can fully participate in reproduction (optimization).

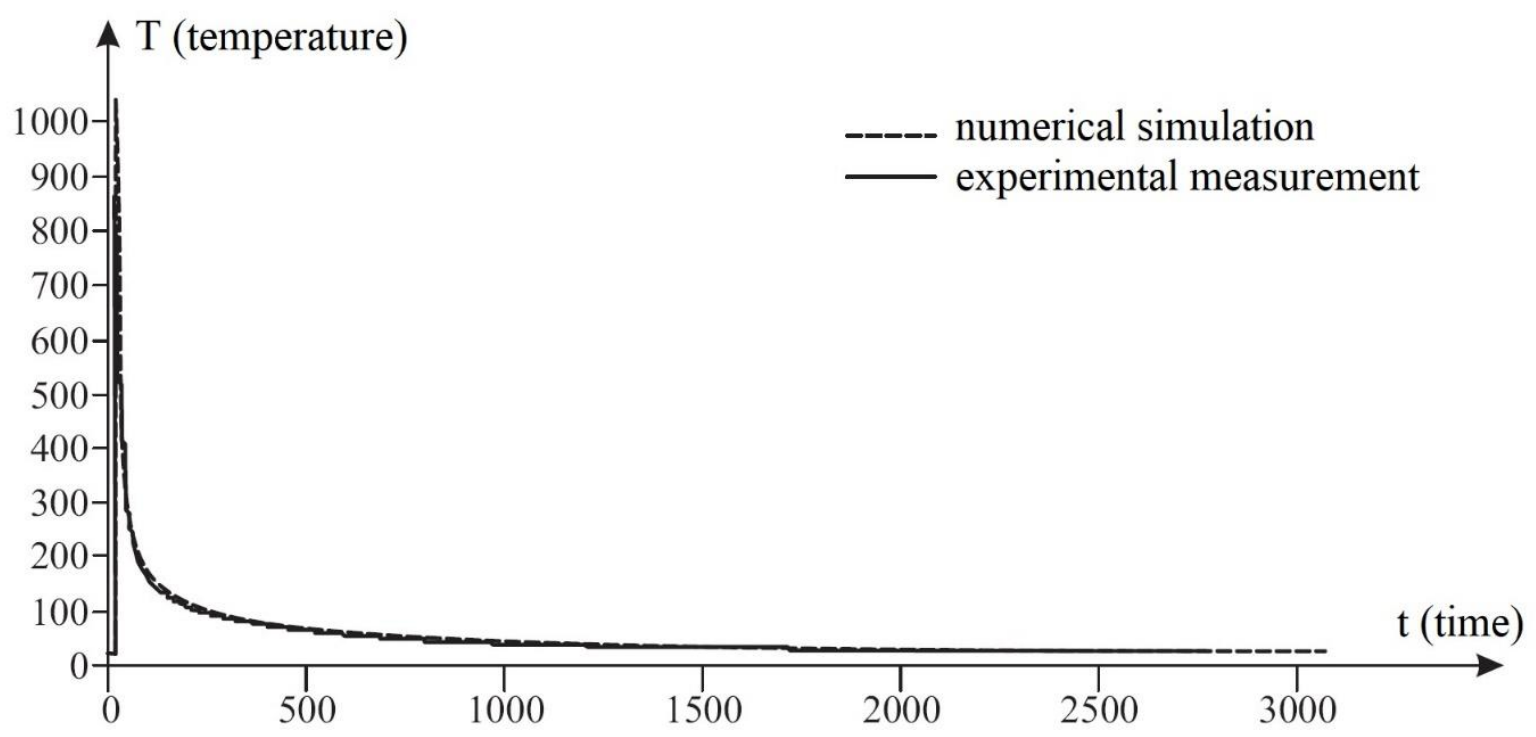

Fig. 5 Comparison of temperature diagrams during the experimental measurement and numerical solution - at the location of thermocouple T1

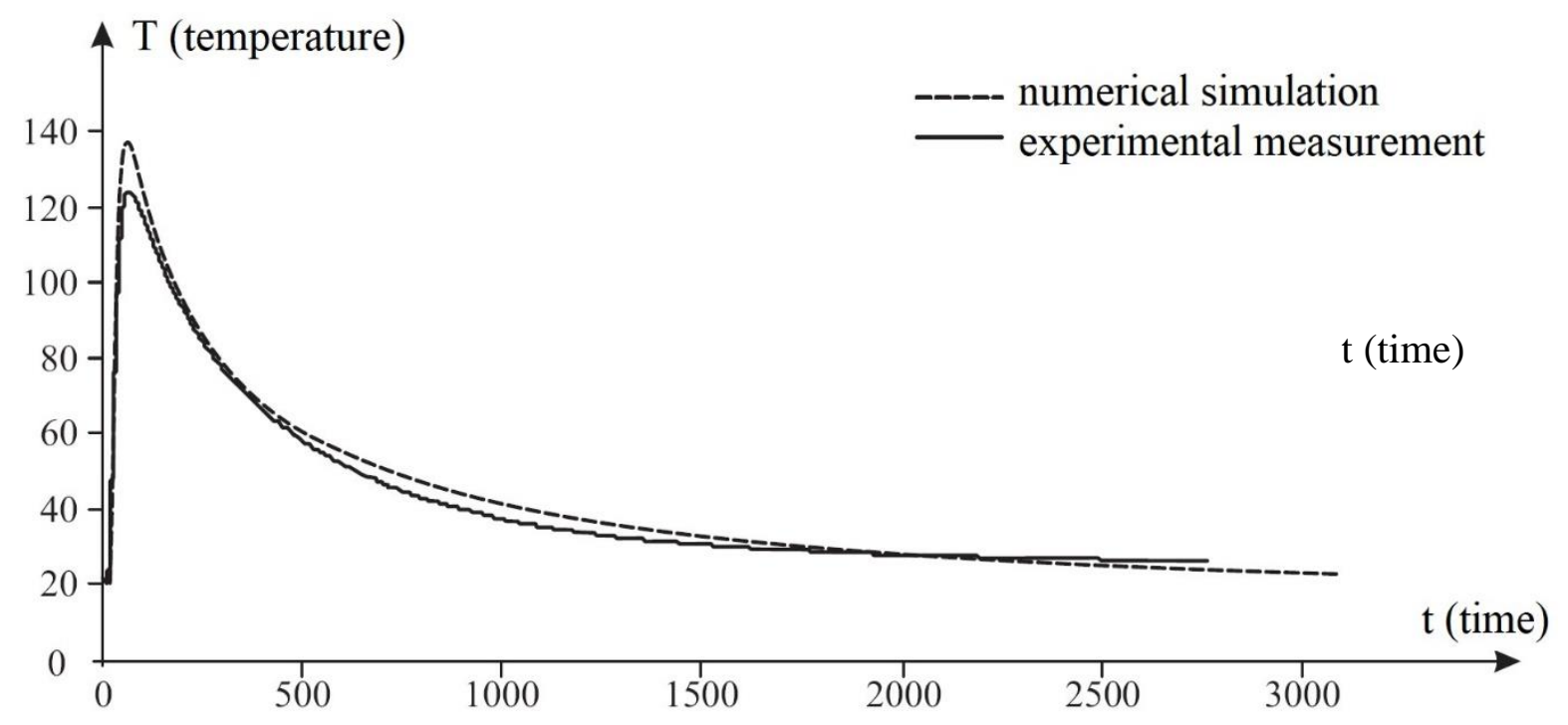

Fig. 6 A comparison of temperature diagrams during the experimental measurement and numerical solution - at the location of thermocouple 
A detailed scheme of the combination of the theory of genetic algorithm and numerical simulation is shown in Fig. 8.

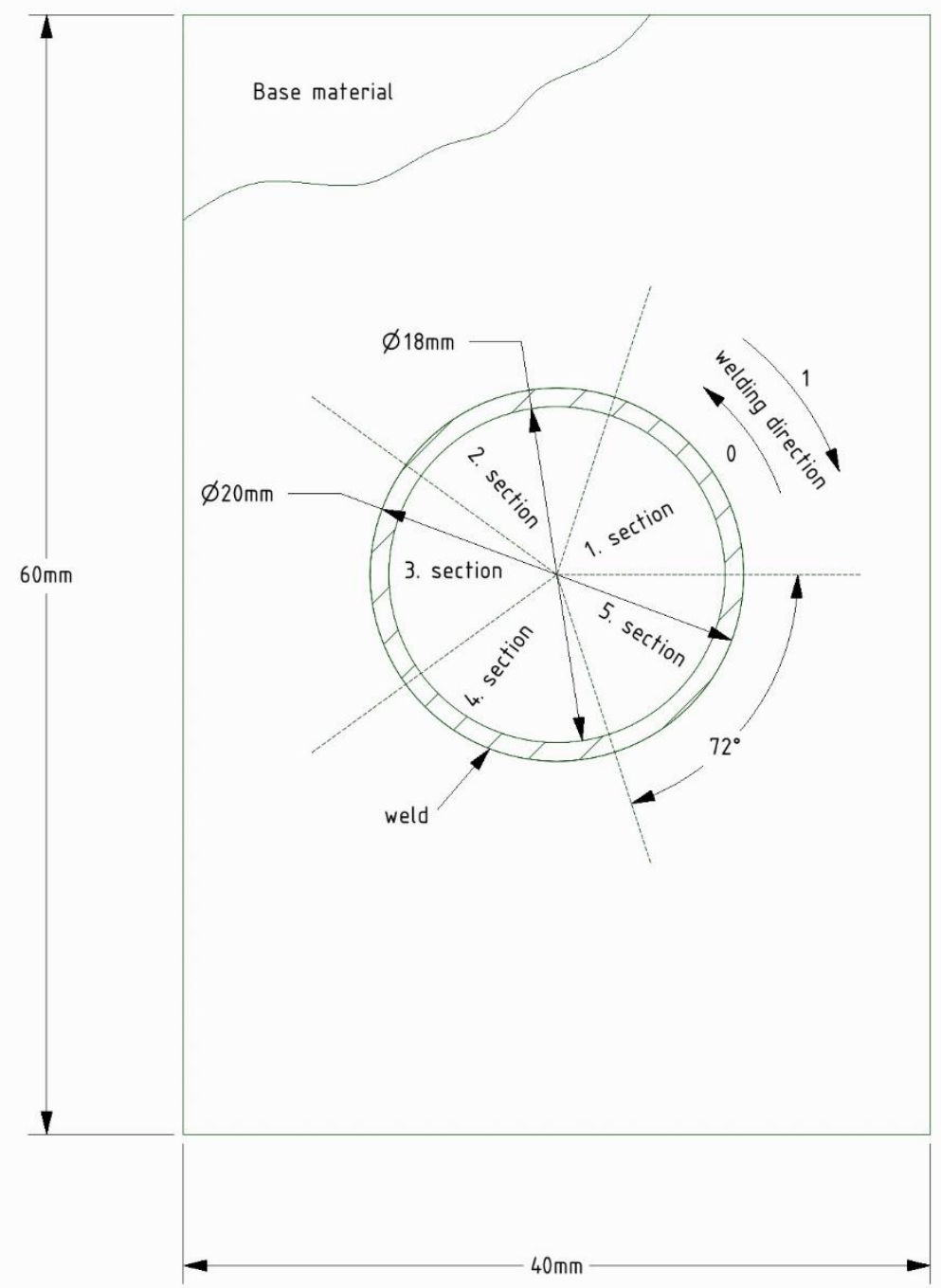

Fig. 7 Welding model of the additional material in an opening 


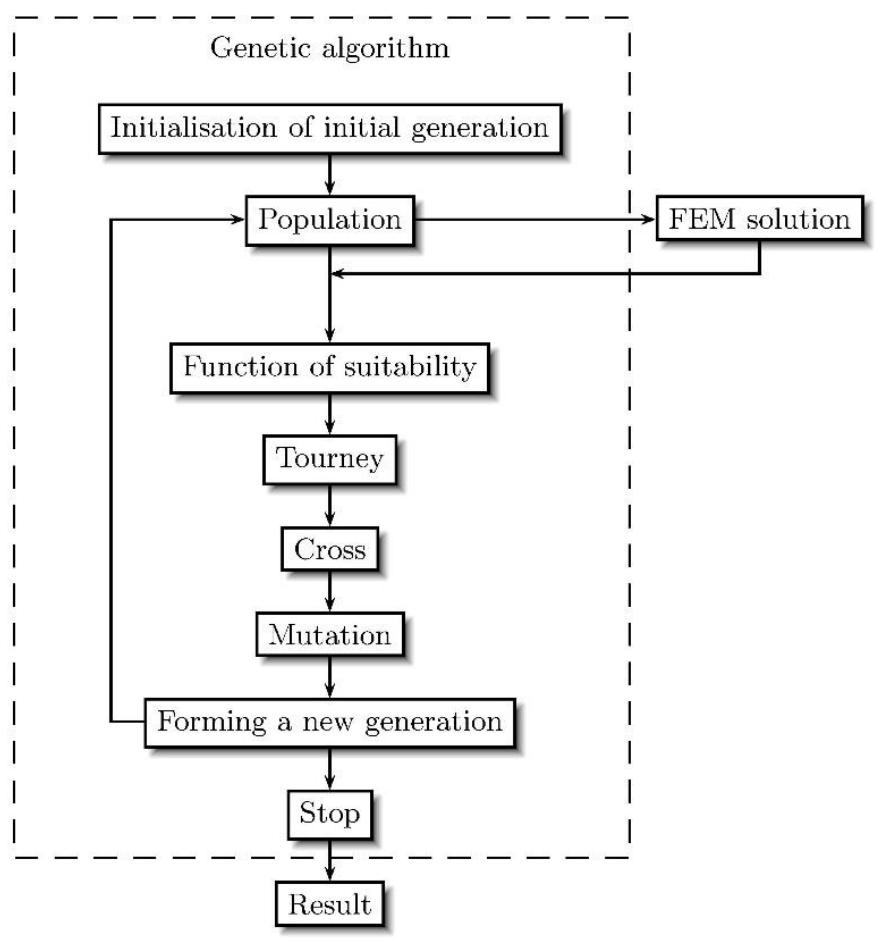

Fig. 8 Applying the genetic algorithm template during a numerical simulation [3]

The basic parameters of the genetic algorithm used for optimization are shown in Table 1.

Table 1: Genetic algorithm parameters

\begin{tabular}{|l|c|}
\hline Number of bits & 10 \\
\hline Population size & 30 \\
\hline Number of generations & 42 \\
\hline Probability of mutation & $1 \%$ \\
\hline Probability of crossing & $85 \%$ \\
\hline
\end{tabular}

\section{$5 \quad$ Results of the welding process optimization by genetic algorithm}

Figure 9 shows the diagram of maximum deformations during the optimization process. The values in the graph are always the average values in a given generation (30 strings). 


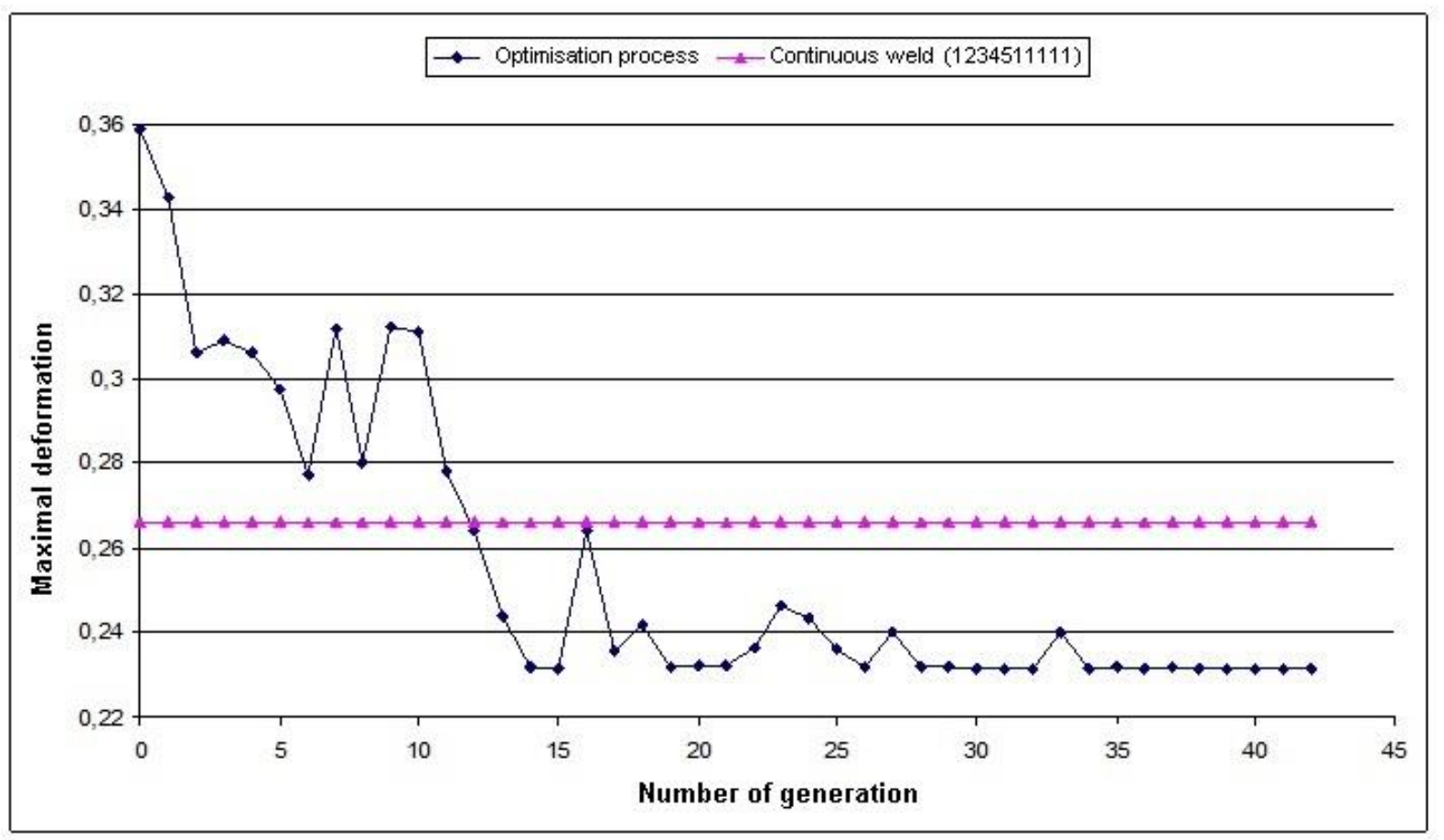

Fig. 9 Maximum displacement during the optimization process

In the graph, the comparison of the maximum deformations obtained by the optimization process and the deformations obtained by continuous welding (gradual welding of the sections $1,2,3,4,5$ in the anti-clockwise direction) can be observed.

\section{CONCLUSION}

The complexity of the welding process optimization is rooted in the highly non-linear nature of the processes that occur during welding. The article presented is an approximation of how a numerical approach can achieve a solution that approaches or, in some cases, even matches the optimal solution.

In one particular case, it was apparent (Fig. 9) that the resulting state obtained by numerical simulation using the genetic algorithm was better than the classical continuous reinforcement.

\section{ACKNOWLEDGMENTS}

This research was supported by a grant from Slovak Grant Agency VEGA 1/0740/16.

\section{REFERENCES}

[1] D.E. Goldberg. Genetic algorithm in Search, Optimization, and Machine Learning, Addison Wesley, Reading, MA 1989.

[2] L. Chambers. Practical Handbook of Genetic Algorithms, aplications, CRC Press, New York 2001.

[3] V. Kvasnička, J. Pospíchal, P. Tiňo. Evolutionary algorithms, STU, Bratislava 2000 (in Slovak).

[4] Sysweld: Reference manual, ESI Group, 2015.

[5] V. Voštiar. Numerical Analysis of Residual Streses after Welding in Planar Parts, Diploma Thesis, STU Engineering Faculty in Bratislava, Bratislava 2002 (in Slovak). 
[6] R. Jančo, L. Écsi, P. Élesztős. FSW Numerical Simulation of Aluminium Plates by SYSWELD - Part I. Journal of Mechanical Engineering - Strojnicky časopis 2016 (66), No. $1,47-52$.

[7] R. Jančo, L. Écsi, P. Élesztős. FSW Numerical Simulation of Aluminium Plates by SYSWELD - Part II. Journal of Mechanical Engineering - Strojnícky časopis 2016 (66), No. 2, $29-36$.

[8] V.K. Patel, K. Rani. Mechanical and wear properties of friction stir welded 0-6Wt\% nAl2O3 reinforced Al-13Wt\%Si composites. Journal of Mechanical Engineering Strojnícky časopis 2017 (67), No. 1, 77 - 86.

[9] D. Santha Rao, N. Ramanaiah. Process Parametrization for Producing AA6061/TIB2 Composites by Friction Stir Processing. Journal of Mechanical Engineering - Strojnicky časopis 2017 (67), No. 1, $101-118$.

[10] F. Trebuňa, F. Šimčák, J. Bocko. Failure analysis of storage tank. Engineering Failure Analysis 2009 (16), No. 1, 26 - 38.

[11] F. Trebuňa, I. Virgala, M. Pástor, T. Lipták, L. Miková. An inspection of pipe by snake robot. International Journal of Advanced Robotic Systems 2016 (13), No. 5, 1 - 12. 